\title{
Does the provision of high-technology health services change after the privatization of public hospitals?
}

\author{
Zo Ramamonjiarivelo ${ }^{1}$, Ferhat Zengul ${ }^{2} \wedge$, Josué Patien Epané ${ }^{\wedge} \wedge$, Larry Hearld ${ }^{2}$, Luceta McRoy $^{4}$, \\ Robert Weech-Maldonado $^{2} \wedge$
}

${ }^{1}$ School of Health Administration, Texas State University, San Marcos, TX, USA; ${ }^{2}$ Department of Health Services Administration, University of Alabama at Birmingham, Birmingham, AL, USA; ${ }^{3}$ Department of Health Care Administration and Policy, University of Nevada, Las Vegas, NV, USA; ${ }^{4}$ LCMJ Consulting, Beltsville, MD, USA

Contributions: (I) Conception and design: Z Ramamonjiarivelo, F Zengul, L Hearld, R Weech-Maldonado; (II) Administrative support: Z Ramamonjiarivelo, R Weech-Maldonado; (III) Provision of study material: R Weech-Maldonado, F Zengul, L Hearld; (IV) Collection and assembly of data: Z Ramamonjiarivelo, F Zengul; (V) Data analysis and interpretation: Z Ramamonjiarivelo, F Zengul, R Weech-Maldonado, L Hearld, J Patien Epané; (VI) Manuscript writing: All authors; (VII) Final approval of manuscript: All authors.

Correspondence to: Zo Ramamonjiarivelo. Texas State University, 601 University Drive, Encino Hall, Suite 250, San Marcos, TX 78666, USA. Email: zhr3@txstate.edu.

Background: Public hospitals hold a key role in providing health care services especially to individuals without health insurance, those who are partially covered by health insurance, and low income population. However, some of these hospitals have converted to private status. The objective of this study was to assess the effect of the ownership conversion of public hospitals into private status on the provision of high-technology health services.

Methods: This study used a non-experimental longitudinal design based on merged secondary data from the American Hospital Association annual survey, the Area Health Resources File, and the Local Area Unemployment Statistics [1997-2013]. The dependent variable "high-technology health services" was measured using Saidin index. There were 492 non-federal acute care public hospitals ( $\mathrm{n}=8,335$ hospital-year observations) in our sample, of which $104(21 \%)$ converted to private status (75 converted to private not-for-profit and 29 converted to for-profit hospitals). The independent variable "privatization" referred to ownership conversion from public to either private not-for-profit or private for-profit status. We ran two fixed-effects linear regressions to measure the impact of privatization on high-technology services offering.

Results: Our key findings suggested that privatization was associated with a decrease in Saidin index ( $\beta=-0.74 ; \mathrm{P}=0.016 ; 95 \% \mathrm{CI}:-1.34$ to -1.38 ). For-profit privatization was associated with a greater decrease in Saidin index $(\beta=-1.29 ; \mathrm{P}=0.024 ; 95 \% \mathrm{CI}:-2.41$ to -0.17$)$, compared with an insignificant decrease for not-for-profit privatization ( $\beta=-0.56$; $\mathrm{P}=0.106 ; 95 \% \mathrm{CI}:-1.25$ to 0.12 ).

Conclusions: Given the excessive cost of high-technology health services and the change in the hospitals' mission after privatization, privatized hospitals tend to reduce the number of high-technology health services they provide.

Keywords: Public hospitals' privatization; Saidin index

Received: 02 August 2020; Accepted: 28 February 2021; Published: 25 December 2021.

doi: $10.21037 /$ jhmhp-20-111

View this article at: http://dx.doi.org/10.21037/jhmhp-20-111

^ ORCID: Zo Ramamonjiarivelo, 0000-0001-5756-3582; Ferhat Zengul, 0000-0002-8454-1335; Josué Patien Epané, 0000-0003-4936-8044; Larry Hearld, 0000-0002-2304-0246; Luceta McRoy, 0000-0003-2520-5814; Robert Weech-Maldonado, 0000-0002-5005-0909. 


\section{Introduction}

Public hospitals are the main responsible for the delivery of health care services to everyone, regardless of ability to pay or health insurance status (1). In addition, public hospitals are expected to provide medical and allied health educations, engage in research, and administer highly specialized services regardless of profitability (2-4). However, the number of public hospitals in the United States has declined from 1,778 hospitals in 1980 to 956 hospitals in 2018 (46\% decline) $(5,6)$. One underlying cause of this decline is financial crisis, which can result in closures or privatizations of public hospitals $(1,7)$. For instance, roughly 147 public hospitals converted to private status between 1997 and 2009; 80\% (117 hospitals) became private not-for profit (NFP) and 20\% [30] became private for-profit (FP) hospitals (7).

For the purpose of this study, privatization indicates hospital change of ownership from public to either NFP or FP status. It has been one of the strategic moves chosen by government entities that own public hospitals experiencing financial difficulties or in need of some financial stability $(7,8)$. Previous research has demonstrated that privatization may result in improved financial performance $(2,9-12)$, efficiency $(2,13,14)$, and productivity (14). However, other studies have indicated that privatization may lead to a decline in health care quality $(10,15,16)$ and a reduction in access to care $(2,16)$. The improvement in financial performance and efficiency, after privatization, may adversely impact health care quality (10) as well as the provision of uncompensated care $(11,17)$.

Changes in management and hospital mission, after privatization, may also offer an opportunity to overhaul service provision. This may include the provision of high-technology health services or clinical services that are "designed to solve certain human health problems, to improve human health conditions, or to improve the precision of diagnosis" [p13 in (18)]. These services may include specialized services, such as organ transplantation, burn care, fertility, medical/surgical/neonatal intensive care, cardiac, emergency department, cancer, neurological, and HIV-AIDS services. They also include services that require a certain level of technological innovation, such as virtual colonoscopy, shaped beam radiation system, and extracorporeal shock wave lithotripsy. Both the initial capital investment and operational cost for high-technology services can be very high and have been identified as major contributors to the escalating health care costs $(19,20)$.
However, high-technology services can also contribute to health care improvement, such as more accurate diagnostics, minimally invasive procedures, increased use of outpatient services versus inpatient hospital stay, shorter hospital stay, better health outcomes, and increased longevity (20).

Relatively few studies have explored the impact that privatization may have on the provision of high-tech services. Prior studies have found that privatized hospitals tended to terminate services that are essential but deemed unlucrative, such as trauma center $(2,9)$, alcoholism and drug abuse therapeutic services, and HIV-AIDS services (2). However, these studies tended to explore the impact of privatization on a limited number of high-tech services. Furthermore, one study focused on privatization of public hospitals to NFP status in only three states (2) and the other study was limited to privatization data through 1998 (9).

The purpose of this study is to build on prior studies by assessing the change in the overall provision of hightechnology medical services following privatization using longitudinal data from 1997-2013. Furthermore, the study uses the Saidin-index, which is a comprehensive measure of the high-technology services provided by each hospital. The measures of high-technology services included in the Saidin-index are based on previous literature that has identified these services as indicators of hospitals' hightechnology capability (21-23). Finally, the study examines whether the provision of high-technology medical services differs between NFP and FP privatizations.

\section{Conceptual framework}

This study applied the agency and property rights theories. Both theories have been used to examine hospital performance after privatization $(14,24)$. These theories explain managerial behavior based on the organization's ownership type. Public hospitals in the United States (U.S.) are the possessions of the citizens of a state, county, or city, who are represented by the federal, state, or local government and as such they directly or indirectly operate under the control of elected officials (25). Public hospitals generate financial capital from public funding in the form of tax revenues as well as tax-exempt bonds (26). Given that public hospitals receive funding from the public, their principal purpose is to meet the needs of the public by providing health care and delivering specialized services to all patients regardless of financial or health insurance status. For instance, 108 public hospitals members 
of America's Essential Hospitals, which account for roughly $2 \%$ of all US community hospitals, provided $18 \%$ of all uncompensated care of the nation ( $\$ 7.8$ billion) in 2014 (27). While all hospital types are expected to maintain a viable financial profile, public hospitals tend not to focus on making profit only and are more likely to provide specialized services, regardless of profitability, compared with private hospitals (3). In addition, profits gained by public hospitals are usually deposited in the public treasury and not distributed among the owners and managers (25).

Private not-for-profit (NFP) hospitals are tax-exempt charities as determined by section 501 (c) (3) of the U.S. Internal Revenue Code. They are owned by faith-based or other secular organizations. Given their tax-exempt status, the NFP hospitals' mission is to provide high-quality health care, medical education, and research with a nonprofit seeking motive (28). These hospitals are required to provide both compensated and uncompensated care on condition that it does not jeopardize their financial stability (29). NFP hospitals raise their capital from philanthropists' donations and tax-exempt bonds. Yet, giving donations does not guarantee the donors the right to receive excess revenues over costs, which are required to be reinvested in the hospital. In addition, the funds from the sale of the hospital cannot be given to philanthropists; they are invested in a foundation for the good of the community $(28,30,31)$.

In contrast to NFP, for-profit (FP) hospitals are owned by investors and their primary goal is to grow investors' wealth. Taking into consideration their profit-seeking motive, FP hospitals are not exempt from property, sales, and income tax, and they are not required by law to deliver uncompensated care. Not like public and NFP hospitals, FP hospitals' shareholders are legally entitled to receive dividend and financial gain on hospital sale among themselves $(28,30,31)$.

Agency theory explains the conflict regarding the relationship between the principal (the owner of the organization) and the agent (the manager or management team), who is hired by the principal to manage the organization. Agency theory suggests that the principal and the agent have diverging plans and objectives. The inability to converge the plans and objectives of the agent with those of the principal may result in poor organizational performance. The agent's major agenda is to achieve his or her own objectives even at the expense of the principal's objectives (24,32), and it can be challenging and pricey for the principal to oversee the agent's behavior (33). According to agency theory, and in the case of private firms, the principal can offer some financial incentives to the agent for his or her commitment to the principal's agenda. Managers of profit maximizing private firms are rewarded in term of co-ownership through stock options as they engage in strategies that improve financial performance. Managers of private not-for-profit organizations may receive some financial incentives at the discretion of the Board of Directors or "Compensation Committee", in terms of bonus, increase in annual compensation, and threat of executive turnover $(34,35)$. Public organizations, in contrast, are constrained in their ability to use financial incentives to reward management performance. Decisions regarding compensations of public hospitals' managers are made at public meetings (36). The citizens, who are the major stakeholders of public hospitals, may be reluctant to offer generous financial compensation to managers (36). Furthermore, the relationship between the principal and the agent of public organizations is mediated by politicians, resulting in two principal-agency relationships: the relationship between the public, who is the owner (as principal) and the politicians (as agents) and the relationship between the politicians (representing the public) and the managers (as agents) (32). Politicians are powerful entities who can impose their agenda, which might facilitate their re-election, but might negatively impact performance $(13,24,32)$. Politicians, on the other hand, do not have power to directly interfere in management practices of privately-owned organizations. Thus, the principals of private organizations are better able to align their interests and objectives with those of the agent than the principals of public organizations. Since privatization is a turn-around strategy, privatized hospitals can freely implement drastic cost reduction strategies, which may include the cessation of some high-technology services. Therefore, based on agency theory, we hypothesize that:

Hypothesis 1: Public hospitals reduce the number of hightechnology health services following privatization.

Property rights theory (PRT) suggests that giving managers the right to make decisions regarding the use of an asset as well as ownership of the residual income is the most effective incentive for managers to make profit-maximizing decisions, which consequently increases managers' financial compensation $(37,38)$. Private FP hospitals are profit maximizers; their primary goal is to satisfy their shareholders. Shareholders are allowed to distribute residual income among themselves and managers, as well as sell their shares to other investors if they do not get the highest rate of return on their investments $(24,38)$. Therefore, managers 
will do their best to satisfy investors by maximizing their wealth. Managers may implement cost reduction strategies such as discontinuing expensive and/or unprofitable hightechnology services to increase profit. Unlike private FP hospitals, private NFP hospitals are utility maximizers. Given their tax-exempt status, private NFP hospitals are expected to meet the needs of the community. A study of the Congressional Budget Office found that NFP hospitals are more likely to provide unprofitable specialized services such as emergency room care and labor and delivery services compared with FP hospitals (29). Also, NFP hospitals are not permitted to allocate residual income among the donors, the board of directors, or the managers (24). Therefore, the managers of NFP hospitals are not as motivated as the managers of FP hospitals with respect to profit maximization. While the Chief Executive Officers of NFP hospitals are not given ownership right to the hospitals, based on financial performance, they may receive compensation based on the levels of high-technology services provided by the hospital (39). Consequently, the managers of NFP hospitals may not be as motivated as the managers of FP hospitals to aggressively cut costs by closing expensive and/or unprofitable high-technology services. Thus, according to PRT, we hypothesize that:

Hypothesis 2: Public hospitals privatized to FP status will have a larger decrease in bigh-technology health services level compared with hospitals privatized to NFP status.

\section{Methods}

\section{Data}

Our study combined three publicly available secondary data from: (I) the American Hospital Association (AHA) Annual Survey, (II) the Area Health Resources File (AHRF), and (III) the Local Area Unemployment Statistics (LAUS) from the Bureau of Labor Statistics. The AHA data file contains hospital profile variables such as ownership status, the number of hospital beds, teaching status, multihospital system affiliation, the size of the health care workforce, and the list of services provided by each hospital. The AHRF data file contains county-level demographic, health care workforce, and economic data. The LAUS data file provides unemployment rates for metropolitan areas, cities, and counties (monthly and annual estimates). The AHA data are the mostly used data for studies of US hospitals and the AHRF data are the mostly used data with respect to countylevel variables. The LAUS has the complete unemployment rate data at the county level.

\section{Sample}

Our sample was comprised of all publicly owned, nonfederal, community hospitals in the U.S. These hospitals were tracked each year from 1997 to 2013. Data after 2013 were not included in our study years due to the major changes in the US healthcare system after 2013. The full implementation of the Affordable Care Act (ACA), signed into law 2010, was in 2014. Some provisions of the ACA to improve access and quality of care while enhancing efficiency (as seen in Hospital value-based purchasing programs) may affect the provision of high-technology health care services. In the same vein, the Medicare Access and CHIP Reauthorization Act (MACRA), signed into law in 2015 and implemented in 2017, which involves some fundamental changes in physician reimbursement from treating Medicare patients may also affect the provision of high-technology services. Also adding more years to our study period of 17 years will lead to additional attrition of hospitals and result in smaller sample size. As we add more years to the data, the number of hospitals that have missing data, with respect to the dependent variable, increases and they need to be dropped from the sample. Our initial sample contained 1,247 public hospitals. To build our study sample, we excluded the following hospital types: hospitals that converted to a skilled nursing $(n=4)$ or an ambulatory care organization $(n=1)$; critical access hospitals $(n=578)$ because they have a special Medicare reimbursement rate at $101 \%$ of reasonable costs and they are not subject to both Inpatient and Outpatient Prospective Payment Systems (40); hospitals that experienced a merger or an acquisition $(n=8)$; hospitals with incomplete data, with respect to the dependent variable, throughout the study period $(n=85)$; hospitals that underwent several changes in ownership status $(n=32)$; and hospitals that closed $(n=47)$. The final study sample included 492 public hospitals (8,335 hospitalyear observations).

\section{Measures}

\section{Dependent variable}

The number of high-technology services owned by a hospital was measured using a high-technology index "the Saidin index", which was a continuous variable and consisted of the sum of the weighted binary variables from the AHA survey on facilities and services that indicated the presence 
or absence of a particular high-technology service in a particular hospital $(23,41)$. In the Saidin index, the number of services increased as new technologies become available and as these technologies were added to the AHA survey. For instance, the number of high-technology services increased from 53 in 2005 to 68 in 2010 as new technologies such as simulated rehabilitation environment, endoscopic retrograde cholangiopancreatography, and assistive technology centers were added (see Table S1). The weights indicated the rareness of a particular high-technology service and were calculated by finding the proportion of hospitals that did not possess the high-technology service (42). For instance, a weight of 0.97 in 2010 for a robot-assisted walking therapy indicates that 97 percent of the U.S. hospitals did not have this particular high-technology service in 2010; only $3 \%$ of all US hospitals provided robot-assisted walking therapy. In the denominator of the Saidin index weight calculations, all US hospitals were included because a high-technology service was rare if only a few hospitals provided that service. Thus, higher Saidin index scores indicated the use of high-tech services with a higher degree of rareness (23).

Variable "count index" was used as the dependent variable in a sensitivity analysis. Count index consisted of the total number of all high-tech services provided by a hospital in a particular year. It was a binary variable coded as " 1 " if the hospital provided the service in a particular year and coded as " 0 " if the hospital did not.

\section{Independent variables}

For Hypothesis 1, privatization was a binary variable recoded as " 1 " if the hospital converted to private status (the year of privatization and following years were recoded as 1 ) and " 0 " if the hospital remained public $(12,14)$. For Hypothesis 2, privatization had two dummy variables. The dummy variable "privatization to for-profit status" was recoded as " 1 " if the hospital converted to private for-profit (the year of privatization and following years were recoded as " 1 ") and " 0 " if the hospital stayed public. The other dummy variable "privatization to not-for-profit status" was recoded as " 1 " if the hospital converted to private not-forprofit (the year of privatization and subsequent years were coded as " 1 ") and " 0 " if the hospital stayed public $(12,14,43)$.

\section{Control variables}

This study included organizational and environmental variables that may influence the use of high-technology medical services as control variables $(44,45)$. Organizational variables included: hospital size, teaching status, outpatient mix, occupancy rate, Medicare mix, Medicaid mix, multihospital system membership, participation in a health network, and contract management $(12,14)$.

Environmental variables (county level) included the following: per capita income, unemployment rate, percentage of people who were $\geq 65$-year-old, number of active physicians per 1,000 population, yearly change in the unemployment rate, Medicare Advantage penetration, excess capacity. In addition, Herfindahl-Hirschman Index measured at the Health Service Area (HSA) level was included as a control variable $(12,14)$. Table 1 summarizes the operational definitions of the variables (14).

\section{Statistical analysis}

Our study used a non-experimental longitudinal design using 1997-2013 data. Cross-tabulations and ANOVAs were used to describe the data, followed by hospital and year fixed-effects linear regression models. A fixed-effects (FE) model controlled for unobservable variables that remain unchanged over time but may be associated with the independent variables and may contribute to betweenhospitals variations. As such, a FE model measures withinhospital variations regarding the provision of hightechnology medical services. Failing to do so may bias the results due to omitted variables $(12,14,46,47)$. We modeled the FE linear regressions as follow (14):

(I) Hypothesis 1:

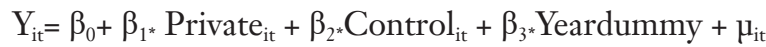

(II) Hypothesis 2:

$\mathrm{Y}_{\mathrm{it}}=\beta_{0}+\beta_{1^{*}}$ Privateprofit $_{\mathrm{it}}+\beta_{2^{*}}$ Privatenoprofit $_{\mathrm{it}}+$ $\beta_{3^{*}}$ Control $_{\text {it }}+\beta_{4^{*}}$ Yeardummy $+\mu_{\mathrm{it}}($ Hypothesis 2$)$

Where:

- Y: dependent variable;

- $\beta_{0}$ : intercept;

- Private: conversion from public to private status;

- Privateprofit: conversion from public to for-profit status;

- Privatenoprofit: conversion from public to not-forprofit status;

- Control: control variables (organizational and market characteristics);

- Yeardummy: year dummy variables;

- i: individual hospital;

- t: each individual year;

- $\mu$ : error term.

Our dependent variables Saidin index and count index (for sensitivity analysis) were both approximately normal, 
Table 1 List of variables and operational definitions (14)

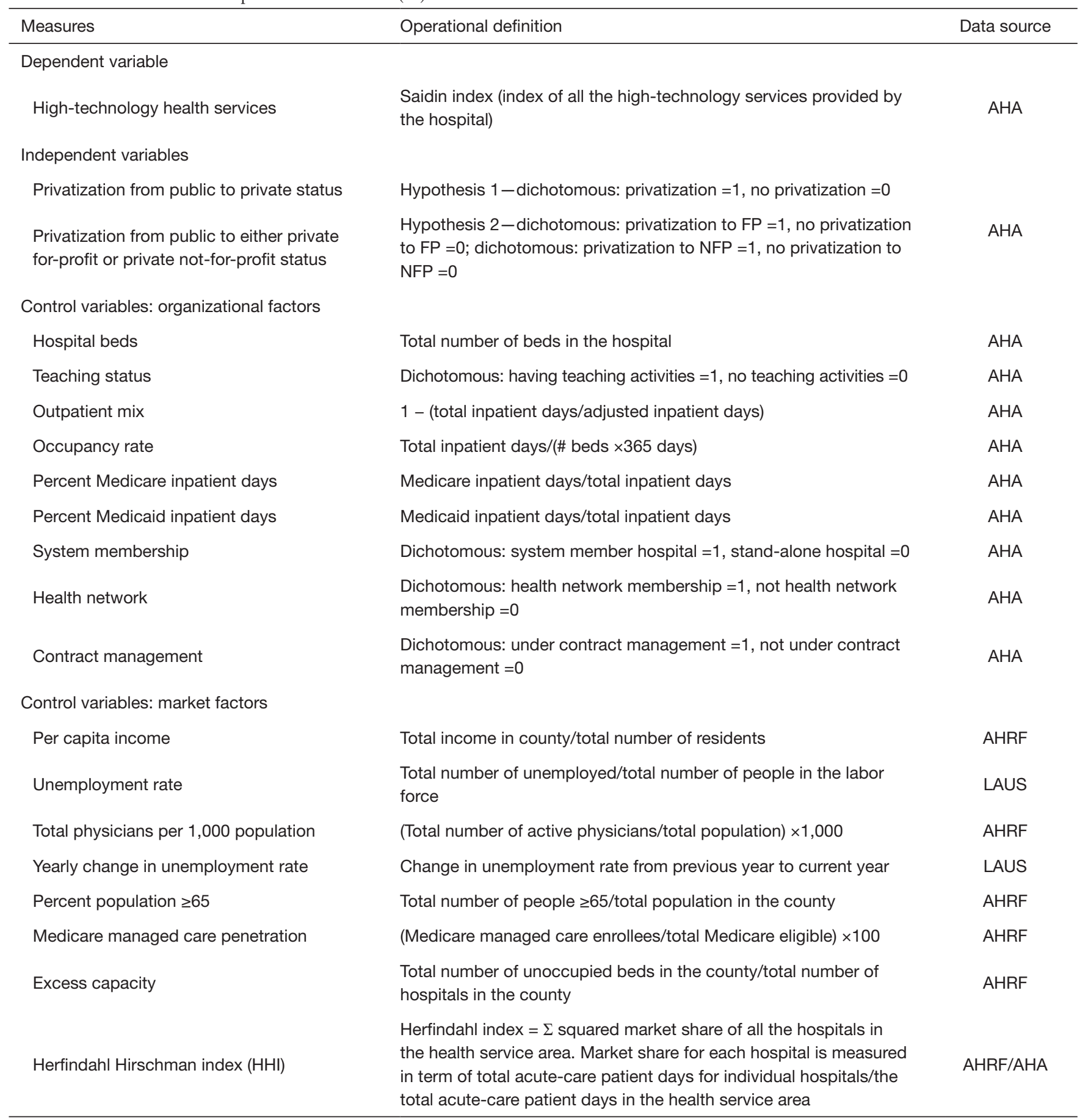

Table adapted from ref (14). AHA, American Hospital Association Annual Survey; AHRF, Area Health Resources Files; LAUS, Local Area Unemployment Statistic.

based on skewness and kurtosis (48-50). None of our independent variables had multicollinearity issues. To test Hypothesis 2, the "lincom" command in STATA was used after the regression analysis on the impact of privatization to either NFP or FP status on high-technology services level. "Lincom" stands for linear combination, this command 
asks STATA to compute the difference between the beta coefficients of NP and NFP privatizations and assess whether that difference is statistically significant. Software SAS 9.2. and STATA 14 were used to clean and analyze the data, respectively.

\section{Results}

One hundred and four hospitals (21\%) privatized among the 492 hospitals in our study sample. Seventy five hospitals (72\%) converted to NFP and 29 hospitals (28\%) converted to FP status among the 104 hospitals that privatized. With regards to the 85 hospitals that did not have complete data throughout the study period and were removed from our study sample, $33 \%$ were affiliated with multihospital systems, $14 \%$ were under contract management, $17 \%$ were health network participants, and $19 \%$ were teaching hospitals. On average, the number of beds was 166 , occupancy rate was $56 \%$, and the Saidin index was 5.43 .

Table 2 summarizes the descriptive statistics of our study sample by type of privatization. The Saidin index before FP privatization was the lowest (4.72) and the Saidin index after NFP privatization was the highest (11.30). Hospitals privatizing to NFP had the highest average number of beds (199). They were also more likely to be built in counties with the highest per capita income $(\$ 33,446)$ as well as highest Medicare Advantage penetration (16\%). Hospitals privatizing to FP status had the highest percentage of hospitals affiliated with multihospital systems (71\%) and highest Medicare mix (56\%), but the lowest percentage of teaching hospitals (13\%), the lowest Medicaid mix (18\%), and the lowest occupancy rate (49\%).

The results of the fixed-effects linear regressions are summarized in Table 3. After controlling for organizational and environmental factors, privatization was associated with a decrease in Saidin index $(\beta=-0.74 ; \mathrm{P}=0.016 ; 95 \%$ CI: -1.34 to -1.38 ). Therefore, hypothesis 1 was supported. Hypothesis 2 was partially supported; privatization to FP was associated with a greater decrease in Saidin index $(\beta=-1.29, \mathrm{P}=0.024 ; 95 \% \mathrm{CI}:-2.41$ to -0.17$)$ compared with a non-significant decrease for privatization to NFP $(\beta=-0.56$; $\mathrm{P}=0.106$; $95 \% \mathrm{CI}:-1.25$ to 0.12 ). However, the results from the lincom command showed that the difference in the levels of high-technology services between FP and NFP privatizations was not statistically significant $($ coefficient $=$ 0.73; $\mathrm{P}=0.252$; $95 \%$ CI: -0.52 to 1.99 ).

The results of the sensitivity analysis using count index as the dependent variable were similar to the results using
Saidin index. Privatization was associated with a significant decrease in count index $(\beta=-1.03 ; \mathrm{P}=0.007 ; 95 \% \mathrm{CI}:-1.78$ to -0.285 ), but the effect size was greater with count index than Saidin index. In the same vein, FP conversion was associated with a larger reduction in count index $(\beta=-1.72$; $\mathrm{P}=0.015$; $95 \% \mathrm{CI}:-3.11$ to -0.34 ), compared with a smaller and marginally significant decrease for NFP privatization ( $\beta=-0.80 ; P=0.061 ; 95 \%$ CI: -1.64 to 0.04$)$. However, the results from the lincom command indicated that the difference in the levels of high-technology services for FP and NFP privatizations was not statistically significant (coefficient $=0.92 ; \mathrm{P}=0.245 ; 95 \% \mathrm{CI}:-0.63$ to 2.47 ) (table not shown).

With respect to the control variables, the results of privatization from public to private status as well as privatizations from public to NFP and from public to FP status (Table 3) were quite similar. Thus, we report the results of privatizations from public to NFP and from public to FP status (hypothesis 2). Several organizational variables were positively associated with Saidin index: hospital beds ( $\beta=0.01 ; \mathrm{P} \leq 0.001 ; 95 \% \mathrm{CI}$ : 0.01 to 0.02$)$, occupancy rate $(\beta=4.76 ; \mathrm{P} \leq 0.001 ; 95 \% \mathrm{CI}: 3.68$ to 5.84$)$, percent Medicare inpatient days ( $\beta=2.94 ; \mathrm{P} \leq 0.001 ; 95 \%$ CI: 1.77 to 4.107), and contract management ( $\beta=0.51 ; \mathrm{P}=0.026 ; 95 \%$ CI: 0.06 to 0.96$)$. The variables outpatient mix $(\beta=-4.00$; $\mathrm{P} \leq 0.001 ; 95 \%$ CI: -5.79 to -2.21$)$ and multihospital system membership ( $\beta=-1.38 ; \mathrm{P} \leq 0.001$; 95\% CI: -1.73 to -1.02 ) were negatively associated with Saidin index.

With respect to market variables, per capita income ( $\beta=0.11 ; \mathrm{P} \leq 0.001 ; 95 \%$ CI: 0.08 to 0.15$)$ and unemployment rate ( $\beta=0.33 ; \mathrm{P} \leq 0.001 ; 95 \% \mathrm{CI}: 0.25$ to 0.40$)$ were positively associated with Saidin index. The variables number of physicians per 1,000 population $(\beta=-0.55 ; \mathrm{P} \leq 0.001 ; 95 \%$ CI: -0.86 to -0.24$)$, yearly change in unemployment rate $(\beta=-1.47 ; \mathrm{P} \leq 0.001 ; 95 \% \mathrm{CI}:-2.13$ to -0.82$)$, excess capacity $(\beta=-0.008 ; \mathrm{P}=0.006 ; 95 \% \mathrm{CI}:-0.01$ to -0.002$)$, and HHI $(\beta=-3.27 ; \mathrm{P} \leq 0.001 ; 95 \%$ CI: -4.64 to -1.90$)$ were negatively associated with Saidin index.

\section{Discussion}

This study assessed the effect of the privatization of public hospitals on the provision of high-technology health services. It further explored whether privatization to FP leads to a larger reduction in high-technology services delivery relative to privatization to NFP. Based on the agency theory and PRT theory and using the Saidin index to measure the overall level of high-technology services offered 
Table 2 Cross-tabulations and analysis of variance $(\mathrm{n}=8,335)^{\mathrm{a}}(14)$

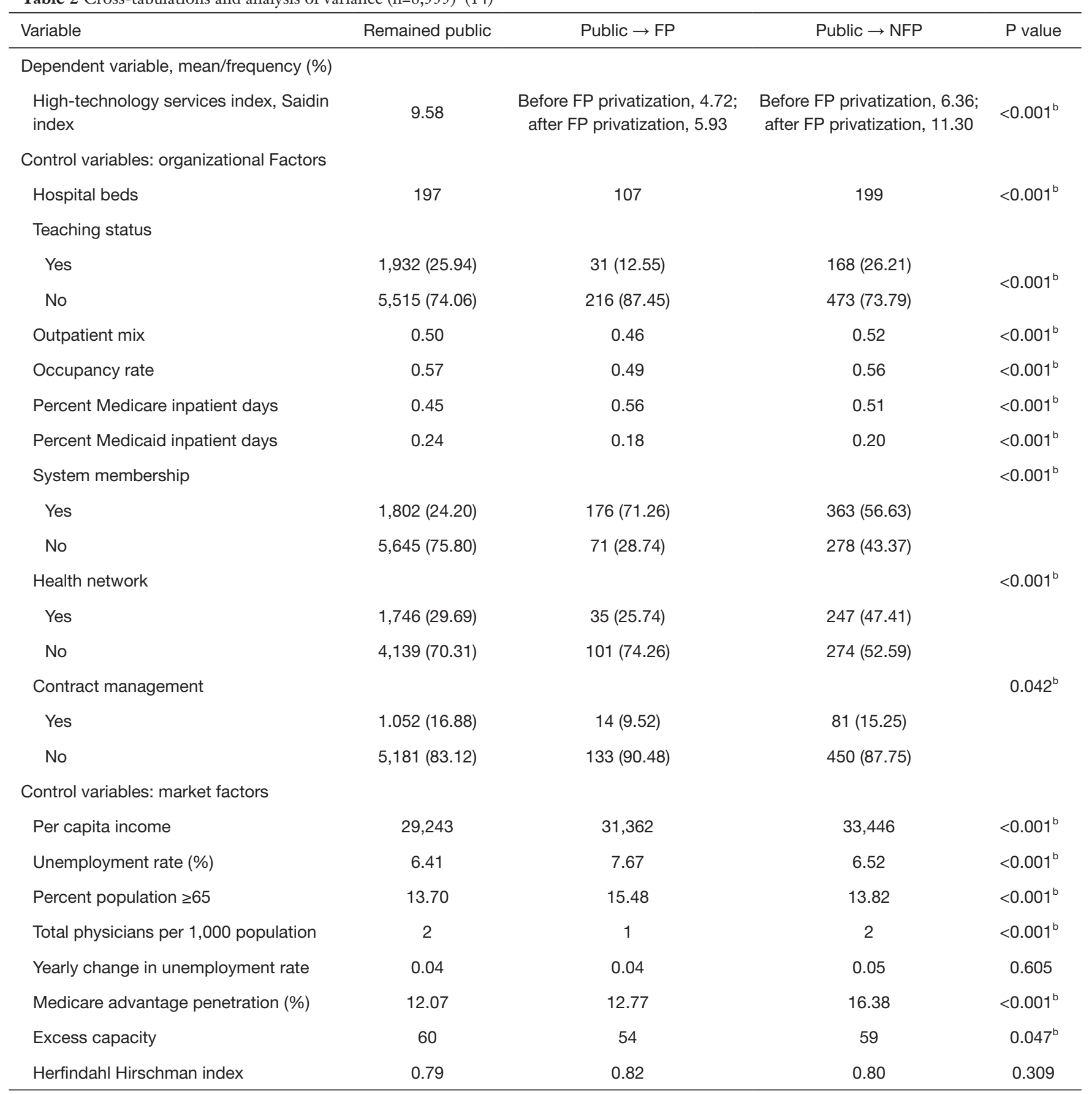

a , sample size and frequencies are expressed in hospital-year observations; ${ }^{\mathrm{b}}$, statistically significant at $\mathrm{P} \leq 0.05$.

by each hospital, our key findings suggest that the level of high-technology services is reduced after privatization. This finding is supported by prior studies; privatized hospitals discontinue or terminate some high-technology services such as emergency rooms, trauma centers, intensive care units, and cardiac services $(2,9,51)$. Considering the managerial flexibilities that private hospitals tend to have, it may be easier for privatized hospitals to discontinue 


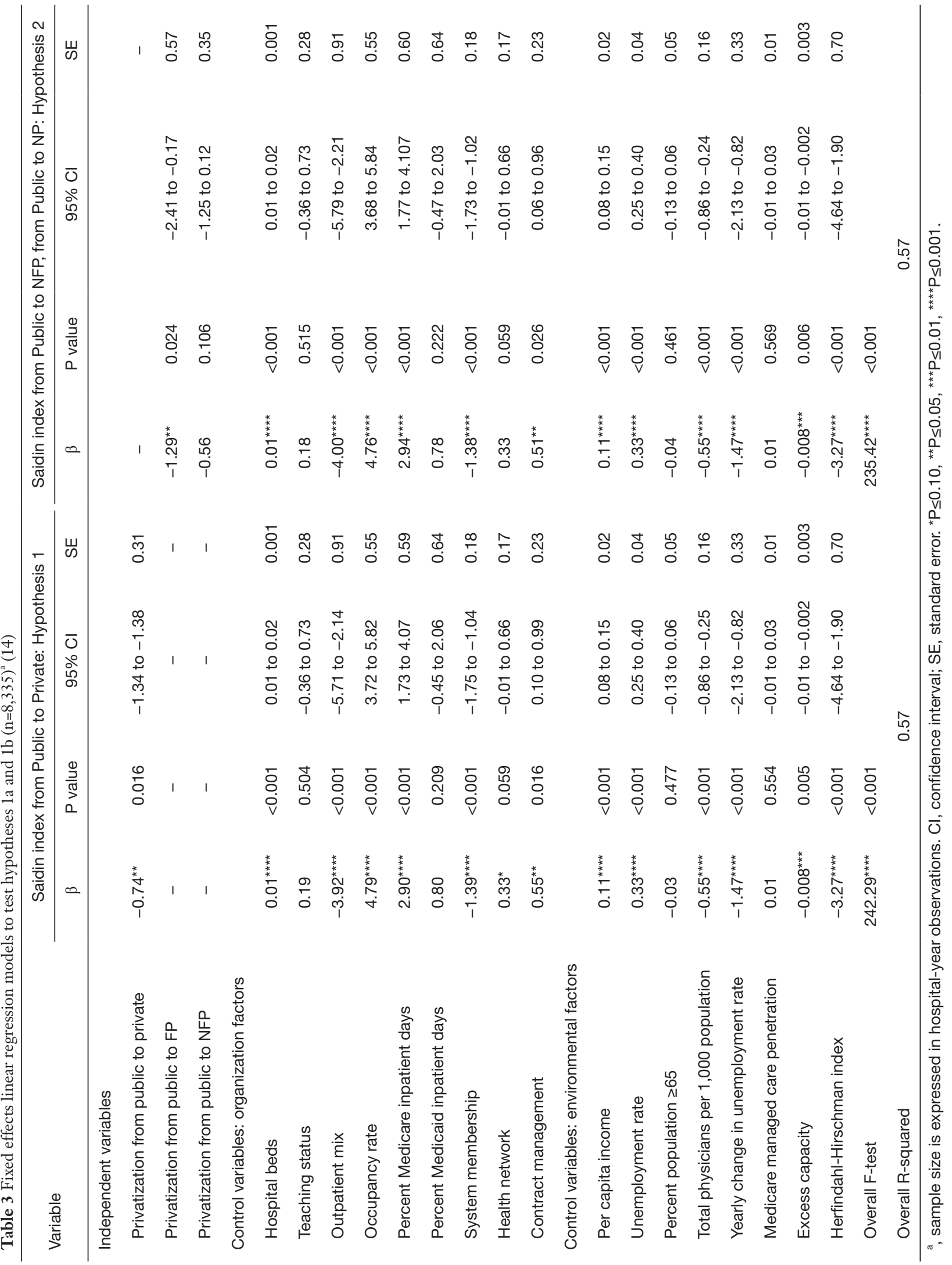


expensive and/or unprofitable high-technology services than for public hospitals. As providers of last resort, public hospitals are more likely to provide the services needed by the community including high-technology services. For instance, 131 public hospitals affiliated with America's Essential Hospitals own $42 \%$ of all the U.S. burn care beds, $34 \%$ of level one trauma centers, and $25 \%$ of pediatric intensive care beds (4). In addition, privatized hospitals may have a greater independence choosing the kind of hightechnology services to provide than public hospitals.

Furthermore, our finding suggests that FP privatization is more likely to be associated with a greater reduction in high-technology services offering, compared with a non-significant reduction after NFP privatization. Since managers of FP hospitals face a greater pressure to maximize profit than NFP hospitals and are better compensated based on hospital's financial performance than managers of NFP hospitals, they may focus on closures of some high-technology services based on financial gain, patient mix, and physician staffing (51). Furthermore, NFP hospitals may have greater pressures from medical staff to keep high-technology services than FP hospitals. Therefore, managers of NFP hospitals may be reluctant to drastically reduce the high-technology services provided by the hospitals (39).

We also found some associations between the control variables and the Saidin index. Hospitals that increase in size and experience growth in occupancy rate and Medicare inpatient days are associated with increased provision of high-technology services. Large hospitals and those with higher occupancy rate may have excess resources to invest in high-technology services and the ability to generate economies of scale that allow them to provide high-technology services. Similarly, hospitals that experience growth in Medicare inpatient days are more likely to experience revenue growth, which will allow them to invest in high-tech services. Medicare patients tend to have multiple comorbidities and severe medical conditions. Therefore, hospitals may need to invest in high-technology services to meet the needs of Medicare patients.

Becoming affiliated with a multihospital system is associated with a reduction in high-technology services. Multihospital systems may have some restrictions in the provision of high-technology services to ensure the financial health of its members and the system. Multihospital systems may also coordinate the provision of these services to achieve economies of scale, especially if system hospitals are in the same market.

\section{Managerial implications}

While a reduction in high-technology services provision, after privatization may be a good strategy to reduce expenditures and improve the financial outlook of the hospital, a thorough assessment of the choice of hightechnology services to discontinue is important. Such choice should be based on the needs of the population and the cost-effectiveness of the technologies to ensure that patients have adequate access to the needed services without causing financial stress to hospitals. Some technologies may be highly advanced and costly, and yet the marginal improvements in health care process and outcomes may be minimal. Conversely, privatized hospitals may assess the availability of high-technology services to the community and decide to close those services that are already provided by other facilities to avoid service duplication. This may contribute to overall efficiency at the community level (52). Also, involving physicians in decisions to cut hightechnology services is important since they are the key providers. Outsourcing high-technology services to other nearby facilities may also be a better alternative to closing those services.

\section{Policy implications}

City, county, or state governments that plan to privatize their public hospitals may need to conduct some preliminary studies on provision of high-tech services, after privatization, to ensure continuity of needed services, without imposing a financial burden to the hospital. Community health needs assessment coupled with costbenefit analysis and comparative effectiveness studies may help all parties involved in deciding which high-technology services to discontinue. A tight monitoring of public hospital privatization is important to ensure continuity of needed high-technology services.

\section{Limitations}

This study has some limitations with respect to the data. First, our Saidin index measure failed to include the availability of high-technology services in non-hospital settings (such as imaging centers and hemodialysis clinics) because the AHA data file only included high-technology data among all hospitals. The inclusion of high-technology 
data from outpatient settings may improve Saidin index value (23). Second, we were not able to assess whether privatized hospitals referred their patients to other hospitals or stand-alone clinics after they discontinued the service. The elimination of some services may not dramatically impact access if privatized hospitals outsource those services to stand-alone specialty clinics or health centers. Third, the results from this study are not generalizable to critical access hospitals since they were excluded from this study. Given the different Medicare reimbursement policy for critical access hospitals, they need to be studied as separate entities from non-critical access hospitals.

Fourth, we were not able to assess the availability of high-technology services at the population level, after privatization. Future studies are needed to investigate the effect of public hospital privatization on the level of hightechnology services offered to the population. Finally, we were not able to compare our findings with the findings of comparable empirical studies using data from other countries. Since privatization of public hospitals is a global phenomenon, empirical studies assessing its impact on the provision of high-tech services in other countries are greatly encouraged.

\section{Conclusions}

The key findings from this study suggest that privatization is associated with decreased use of high-technology services, especially for FP conversion. Due to the prohibitive price of high-technology services and the change in hospital's mission after privatization, privatizing hospitals tend to cut the provision of high-technology health services.

\section{Acknowledgments}

Funding: None.

\section{Footnote}

Peer Review File: Available at http://dx.doi.org/10.21037/ jhmhp-20-111

Conflicts of Interest: All authors have completed the ICMJE uniform disclosure form (available at http://dx.doi. org/10.21037/jhmhp-20-111). Dr. RWM reports grants from National Science Foundation, grants from Agency for Healthcare Research and Quality, grants from National Institute on Aging, grants from RAND/Centers for
Medicare and Medicaid Services, outside the submitted work. The other authors have no conflict of interest to declare.

Ethical Statement: The authors are accountable for all aspects of the work in ensuring that questions related to the accuracy or integrity of any part of the work are appropriately investigated and resolved.

Open Access Statement: This is an Open Access article distributed in accordance with the Creative Commons Attribution-NonCommercial-NoDerivs 4.0 International License (CC BY-NC-ND 4.0), which permits the noncommercial replication and distribution of the article with the strict proviso that no changes or edits are made and the original work is properly cited (including links to both the formal publication through the relevant DOI and the license). See: https://creativecommons.org/licenses/by-nc-nd/4.0/.

\section{References}

1. Ko M, Derose KP, Needleman J, et al. Whose social capital matters? The case of US urban public hospital closures and conversions to private ownership. Soc Sci Med 2014;114:188-96.

2. Villa S, Kane N. Assessing the impact of privatizing public hospitals in three American states: Implications for universal health coverage. Value Health 2013;16:S24-33.

3. Horwitz JR. Making profits and providing care: Comparing nonprofit, for-profit, and government hospitals. Health Affairs 2005;24:790-801.

4. Roberson B and Ramiah K. Essential Data: Our Hospitals, Our Patients. May 2020. America's Essential Hospitals. Washington, DC. Available online: https:// essentialhospitals.org/wp-content/uploads/2020/05/ Essential-Data-2020_spreads.pdf

5. National Center for Health Statistics. Health, United States, 2010: With Special Feature on Death and Dying. 2011. Hyattsville, MD. Available online: https://www.cdc. gov/nchs/data/hus/hus10.pdf

6. American Hospital Association. Fast Facts on US Hospitals. 2018. Chicago, IL. Available online: https:// www.aha.org/system/files/2018-02/2018-aha-hospital-fastfacts.pdf

7. Ramamonjiarivelo Z, Weech-Maldonado R, Hearld L, et al. Public hospitals in financial distress: Is privatization a strategic choice? Health Care Management Review 2015;40:337-47. 
8. Fleshler D. Gov. Scott is key to Broward Health's fate. Sun Sentinel, November 30, 2016. Available online: https:// www.sun-sentinel.com/news/fl-broward-health-scott20160414-story.html

9. Shen YC. Changes in hospital performance after ownership conversions. Inquiry 2003;40:217-34.

10. Picone G, Shin-Yi C, Sloan F. Are for-profit hospital conversions harmful to patients and to Medicare? Rand J Econ 2002;33:507-23.

11. Thorpe KE, Florence C, Sieber E. Hospital conversions, margins, and the provision of uncompensated care. Health Affairs 2000;19:187-94.

12. Ramamonjiarivelo Z, Weech-Maldonado R, Hearld L, et al. The privatization of public hospitals: Its impact on financial performance. Med Care Res Rev 2020;77:249-60.

13. Tiemann O, Schreyögg J. Changes in hospital efficiency after privatization. Health Care Manag Sci 2012;15:310-26.

14. Ramamonjiarivelo Z, Epané JP, Hearld L, et al. The impact of privatization on efficiency and productivity: The case of US public hospitals. Journal of Health Care Finance 2016;43:104-23.

15. Shen YC. The effect of hospital ownership choice on patient outcomes after treatment for acute myocardial infarction. Journal of Health Economics 2002;21:901-22.

16. Sloan FA. Hospital Ownership Conversions: Defining the Appropriate Public Oversight Role. NBER/Frontiers Health Policy Res 2002;5:123-66.

17. Desai KR, Lukas CV, Young DW. Public hospitals: Privatization and uncompensated care. Health Affairs 2000;19:167-72.

18. Zengul FD, Weech-Maldonado R, Savage GT. Technological innovations and hospital performance: A systematic review of the literature. Innovation and Entrepreneurship Health 2014;1:13-26.

19. Callahan D. Taming the beloved beast: How medical technology costs are destroying our health care system. Princeton University Press, 2009. Princeton, NJ.

20. Cutler DM, McClellan M. Is technological change in medicine worth it? Health Affairs 2001;20:11-29.

21. Spetz J. The effects of managed care and prospective payment on the demand for hospital nurses: Evidence from California. Health Serv Res 1999;34:993-1010.

22. Zengul FD, Weech-Maldonado R, Ozaydin B, et al. Longitudinal analysis of high-technology services and hospital financial performance. Health Care Manage Rev 2018;43:2-11.

23. Spetz J, Baker LC. Has managed care affected the availability of medical technology? Public Policy Institute of California 1999. San Francisco, CA. Available online: https://www.ppic.org/content/pubs/report/R_599JSR.pdf

24. Tiemann O, Schreyögg J. Investigating the effects of hospital privatization on performance and quality of care. 2010. Available online: https://www.econstor.eu/ bitstream/10419/37374/1/VfS_2010_pid_417.pdf

25. Institute of Medicine. For-Profit Enterprise in Health Care. National Academy Press, 1986. Washington, DC.

26. Institute of Medicine. Financial Capital and Health Care Growth Trends. In: Gray B. editor. For-Profit Enterprise in Health Care. Washington, DC: National Academies Press, 1986.

27. Landry C, Ramiah K, Rangarao S, et al. Essential Data: Our Hospitals, Our Patients. Washington, DC: America's Essential Hospitals, 2016.

28. Institute of Medicine. For-Profit Enterprise in Health Care. Washington, DC: National Academy Press, 1986.

29. US Congressional Budget Office. A CBO Paper: Nonprofit hospitals and the provision of community benefits. CBO, 2006. Washington, DC.

30. Gray BH. Conversion of HMOs and hospitals: What's at stake? Health Affairs 1997;16:29-47.

31. Marsteller JA, Bovbjerg RR, Nichols LM. Nonprofit conversion: Theory, evidence, and state policy option. Health Serv Res 1998;33:1495-535.

32. Cuervo A, Villalonga B. Explaining the variance in the performance effects of privatization. Aca Management Rev 2000;25:581-90.

33. Eisenhardt KM. Agency theory: An assessment and review. Aca Management Rev 1989;14:57-74.

34. Internal Revenue Service. IRS Exempt Organizations (TE/GE) Hospital Compliance Project Final Report. Department of Treasury 2006. Washington, DC.

35. Brickley JA, Van Horn RL. Managerial incentives in nonprofit organizations: Evidence from hospitals. Journal of Law and Economics 2002;45:227-49.

36. Eldenburg L, Krishnan R. Public versus private governance: A study of incentives and operational performance. Journal of Accounting and Economics 2003;35:377-404.

37. Preker AS, Harding A. Innovations in health service delivery: The corporatization of public hospitals. Washington, DC: World Bank Publications, 2003.

38. Tiemann O, Schreyögg J. Effects of ownership on hospital efficiency in Germany. BUR-Business Research 2009;2:115-45.

39. Joynt KE, Le ST, Orav EJ, et al. Compensation of chief 
executive officers at nonprofit US hospitals. JAMA Internal Medicine 2014;174:61-7.

40. Centers for Medicare and Medicaid Services. Critical Access Hospitals - Medicare Learning Network Booklet. CMS 2017. Available online: https:// www.cms.gov/Outreach-and-Education/MedicareLearning-NetworkMLN/MLNProducts/downloads/ CritAccessHospfctsht.pdf

41. Spetz J. The effects of managed care and prospective payment on the demand for hospital nurses: Evidence from California. Health Serv Res 1999;34:993-1010.

42. Zengul FD, Weech-Maldonado R, Ozaydin B, et al. Longitudinal analysis of high-technology medical services and hospital financial performance. Health Care Manage Rev 2018;43:2-11.

43. Pradhan R, Weech-Maldonado R, Harman JS, et al. Private equity ownership of nursing homes: Implications for quality. Journal of Health Care Finance 2014;42:1-14.

44. Barbash GI, Friedman B, Glied SA, et al. Factors associated with adoption of robotic surgical technology in US hospitals and relationship to radical prostatectomy procedure volume. Ann Surg 2014;259:1-6.

45. Ladapo JA, Horwitz JR, Weinstein MC, et al. Adoption and spread of new imaging technology: A case study.

Health Affairs 2009;28:w1122-32.

doi: 10.21037/jhmhp-20-111

Cite this article as: Ramamonjiarivelo Z, Zengul F, Patien Epané J, Hearld L, McRoy L, Weech-Maldonado R. Does the provision of high-technology health services change after the privatization of public hospitals? J Hosp Manag Health Policy 2021;5:37.
46. Allison PD. Fixed effects regression methods for longitudinal data using SAS. SAS Institute, 2005. Cary, NC.

47. Wooldridge J. Introductory econometrics: A modern approach. Cengage Learning, 2012. Independence, KY.

48. Weech-Maldonado R, Laberge A, Pradhan R, et al. Nursing home financial performance: The role of ownership and chain affiliation. Health Care Manage Rev 2012;37:235-45.

49. West SG, Finch JF, Curran PJ. Structural equation models with nonnormal variables: Problems and remedies. In Hoyle RH (Ed), Structural equation modeling: Concepts, issues, and applications. Sage Publications, Inc. 1995:5675. Thousand Oaks, CA.

50. Kim HY. Statistical notes for clinical researchers: assessing normal distribution (2) using skewness and kurtosis. Restorative Dentistry Endodontics 2013;38:52-4.

51. Chollet DJ, Kirk AM. A case-study investigation of charity care and essential service provision following hospital conversion to for-profit status. Public Policy Institute, AARP 1999. Washington, DC.

52. Carey K, Dor A. Trends in contract management: The hidden evolution in hospital organization. Health Affairs 2004;23:192-9. 
Table S1 High-tech services and Saidin index weights for select years

\begin{tabular}{|c|c|c|c|c|c|}
\hline High-tech Services & 1997 & 2000 & 2005 & 2010 & 2014 \\
\hline Lung transplant & & & $99 \%$ & $99 \%$ & $99 \%$ \\
\hline Proton beam therapy & & & & $98 \%$ & $98 \%$ \\
\hline Liver transplant & & & $98 \%$ & $98 \%$ & $98 \%$ \\
\hline Heart transplant & & & $98 \%$ & $98 \%$ & $98 \%$ \\
\hline Pediatric cardiac surgery - & & & $97 \%$ & $97 \%$ & $97 \%$ \\
\hline Burn care & $97 \%$ & $98 \%$ & $97 \%$ & $97 \%$ & $97 \%$ \\
\hline Pediatric diagnostic catheterization & & & $96 \%$ & $97 \%$ & $97 \%$ \\
\hline Robot-assisted walking therapy & & & & $97 \%$ & $97 \%$ \\
\hline Pediatric cardiac electrophysiology & & & & $97 \%$ & $97 \%$ \\
\hline Bone Marrow transplant services & & & $97 \%$ & $97 \%$ & $97 \%$ \\
\hline Kidney transplant & & & $97 \%$ & $96 \%$ & $97 \%$ \\
\hline Intraoperative magnetic resonance imaging & & & & $97 \%$ & $96 \%$ \\
\hline Fertility Clinic & & & $95 \%$ & $96 \%$ & $96 \%$ \\
\hline Other Transplant & & & $97 \%$ & $96 \%$ & $96 \%$ \\
\hline Blood Donor Center & & & $94 \%$ & $95 \%$ & $95 \%$ \\
\hline Freestanding/Satellite Emergency Department & & & $98 \%$ & $95 \%$ & $95 \%$ \\
\hline Electron Beam Computed Tomography (EBCT) & & & $95 \%$ & $95 \%$ & $95 \%$ \\
\hline Tissue transplant & & & $97 \%$ & $95 \%$ & $94 \%$ \\
\hline Pediatric intensive care & $93 \%$ & $93 \%$ & $92 \%$ & $93 \%$ & $93 \%$ \\
\hline Other intensive care & & $94 \%$ & $92 \%$ & $92 \%$ & $91 \%$ \\
\hline Neonatal intermediate care & $90 \%$ & $90 \%$ & $89 \%$ & $89 \%$ & $89 \%$ \\
\hline Computer assisted orthopedic surgery & & & $94 \%$ & $90 \%$ & $88 \%$ \\
\hline Genetic testing/counseling & & & $93 \%$ & $90 \%$ & $88 \%$ \\
\hline Other special care & $88 \%$ & $90 \%$ & $89 \%$ & $89 \%$ & $88 \%$ \\
\hline Virtual colonoscopy & & & $92 \%$ & $88 \%$ & $87 \%$ \\
\hline Positron emission tomography (PET) & $97 \%$ & $95 \%$ & $89 \%$ & $89 \%$ & $87 \%$ \\
\hline Stereotactic radiosurgery & & & $90 \%$ & $87 \%$ & $86 \%$ \\
\hline Shaped beam Radiation System & & & $89 \%$ & $87 \%$ & $85 \%$ \\
\hline Neonatal intensive care & $87 \%$ & $87 \%$ & $85 \%$ & $85 \%$ & $84 \%$ \\
\hline Positron emission tomography/CT (PET/CT) & & & $92 \%$ & $86 \%$ & $84 \%$ \\
\hline Assistive technology center & & & & $88 \%$ & $83 \%$ \\
\hline HIV-AIDS services & $72 \%$ & $75 \%$ & $81 \%$ & $82 \%$ & $83 \%$ \\
\hline Image-guided radiation therapy & & & $94 \%$ & $86 \%$ & $83 \%$ \\
\hline Esophageal impedance study & & & & $86 \%$ & $82 \%$ \\
\hline Adult cardiac surgery & & & $83 \%$ & $82 \%$ & $82 \%$ \\
\hline Intensity-Modulated Radiation Therapy (IMRT) & & & $87 \%$ & $83 \%$ & $82 \%$ \\
\hline Ablation of Barrett's esophagus & & & & $85 \%$ & $81 \%$ \\
\hline Electrodiagnostic services & & & & $84 \%$ & $80 \%$ \\
\hline Ambulatory surgery center & & & & $81 \%$ & $80 \%$ \\
\hline Simulated rehabilitation environment & & & & $83 \%$ & $80 \%$ \\
\hline Cardiac intensive care & $71 \%$ & $74 \%$ & $76 \%$ & $79 \%$ & $80 \%$ \\
\hline Extracorporeal shock waved lithotripter (ESWL) & $90 \%$ & $86 \%$ & $83 \%$ & $80 \%$ & $80 \%$ \\
\hline Robotic surgery & & & $96 \%$ & $87 \%$ & $80 \%$ \\
\hline Adult cardiac electrophysiology & & & & $81 \%$ & $78 \%$ \\
\hline Hemodialysis & & $83 \%$ & $78 \%$ & $77 \%$ & $77 \%$ \\
\hline Adult interventional cardiac catheterization & & & $79 \%$ & $77 \%$ & $75 \%$ \\
\hline Endoscopic ultrasound & & & & $78 \%$ & $74 \%$ \\
\hline Certified trauma center & $84 \%$ & $77 \%$ & $77 \%$ & $75 \%$ & $73 \%$ \\
\hline Single photon emission computerized tomography (SPECT) & $75 \%$ & $74 \%$ & $73 \%$ & $72 \%$ & $72 \%$ \\
\hline Adult diagnostic catheterization & & & $73 \%$ & $72 \%$ & $71 \%$ \\
\hline Endoscopic retrograde cholangiopancreatography (ERCP) & & & & $71 \%$ & $69 \%$ \\
\hline Multi-slice spiral computed tomography $64+$ slice & & & $91 \%$ & $71 \%$ & $64 \%$ \\
\hline Neurological services & & & $67 \%$ & $64 \%$ & $64 \%$ \\
\hline Chemotherapy & & & $62 \%$ & $62 \%$ & $62 \%$ \\
\hline Adult cardiology services & & & & $66 \%$ & $62 \%$ \\
\hline Cardiac Rehabilitation & & & $63 \%$ & $62 \%$ & $61 \%$ \\
\hline Diagnostic radioisotope facility & $56 \%$ & $55 \%$ & $58 \%$ & $59 \%$ & $59 \%$ \\
\hline Full-field digital mammography & & & $90 \%$ & $67 \%$ & $58 \%$ \\
\hline Multislice spiral computed tomography $<64$ slice & & & $64 \%$ & $57 \%$ & $58 \%$ \\
\hline Medical/surgical intensive care & $47 \%$ & $47 \%$ & $52 \%$ & $53 \%$ & $54 \%$ \\
\hline Optical Colonoscopy & & & & $58 \%$ & $52 \%$ \\
\hline Magnetic resonance imaging (MRI) & $66 \%$ & $61 \%$ & $57 \%$ & $52 \%$ & $51 \%$ \\
\hline Breast cancer screening/mammograms & $43 \%$ & $42 \%$ & $47 \%$ & $48 \%$ & $48 \%$ \\
\hline Airborne infection isolation room & & & $51 \%$ & $45 \%$ & $41 \%$ \\
\hline Outpatient surgery & $33 \%$ & $33 \%$ & $38 \%$ & $39 \%$ & $41 \%$ \\
\hline Ultrasound & $37 \%$ & $36 \%$ & $39 \%$ & $39 \%$ & $40 \%$ \\
\hline Emergency Department & $32 \%$ & $31 \%$ & $36 \%$ & $37 \%$ & $39 \%$ \\
\hline Computed-tomography (CT) scanner & $40 \%$ & $37 \%$ & $39 \%$ & $38 \%$ & $38 \%$ \\
\hline Radiology therapeutic & $81 \%$ & $80 \%$ & & & \\
\hline Number of high-tech services & 20 & 22 & 53 & 68 & 68 \\
\hline Number of hospitals used to calculate the weights & 6299 & 6044 & 6349 & 6334 & 6239 \\
\hline
\end{tabular}

The table was sorted by 2014 weights from highest to lowest. 